\title{
Isolation and partial characterisation of secondary metabolites from fish-borne bacterium, Pseudomonas aeruginosa
}

\author{
FARHANA HOQUE ${ }^{1,3}$, T. JAWAHAR ABRAHAM ${ }^{1}$ AND P. JAISANKAR ${ }^{2}$ \\ ${ }^{1}$ Department of Aquatic Animal Health, Faculty of Fishery Sciences, West Bengal University of Animal and Fishery \\ Sciences, Chakgaria, Kolkata - 700 094, West Bengal, India \\ ${ }^{2}$ Indian Institute of Chemical Biology, 4, Raja S. C. Mullick Road, Jadavpur, Kolkata - 700 032, West Bengal, India \\ ${ }^{3}$ ICAR-Central Institute of Freshwater Aquaculture, Regional Research Centre, Rahara, P. O. Rahara \\ Kolkata - 700 118, West Bengal, India \\ e-mail:farhanahoque22@gmail.com
}

\section{ABSTRACT}

Partial characterisation of secondary metabolites of a potent antagonistic bacterium Pseudomonas aeruginosa FARP72 (NCBI GenBank Accession No. KC570343) isolated from the skin mucus of catfish Clarias batrachus was attempted in this study. The antagonistic activity of $P$. aeruginosa was confirmed by cross and parallel streaking methods against three bacterial fish pathogens (Aeromonas caviae, Edwardsiella tarda and $\beta$-haemolytic Streptococcus sp.) and seven human bacterial pathogens viz., Klebsiella pneumoniae, Enterohaemorrhagic Escherichia coli, Escherichia coli, Staphylococcus aureus ATCC 12598, Salmonella Typhi (serovar of Salmonella enterica sub sp. enterica), Vibrio cholerae and Bacillus pumilus. The antibacterial activities of the crude ethyl acetate extract of the whole cell of P. aeruginosa and the spent medium were also tested against the pathogens by well and disc diffusion assays. The ethyl acetate extract of $P$. aeruginosa cells was subjected to column chromatography packed with silica gel (60-120 mm mesh size) using petroleum ether and ethyl acetate in different concentrations as the mobile phase. The compounds of the bioactive fractions were semi purified and partially characterised using thin layer chromatography and mass spectroscopy. The secondary metabolites were identified to be pyrols, quinoline and phenazine compounds. The results suggested that the bioactive fractions of whole $P$. aeruginosa cells have potential antibacterial activity, which can be used as an alternative to conventional antibiotics to control fish and human pathogens.

Keywords: Antagonistic bacterium, Bioactive fractions, Pathogens, Partial characterisation, Pseudomonas aeruginosa, Skin mucus

\section{Introduction}

High stocking density and high feed input came in to play for increasing production in intensive aquaculture practice, which in turn, accompanies several disease problems decreasing growth rate and hence the production. The use of antimicrobials and indiscriminate use of commercial antibiotics in disease prevention results in development of antibiotic resistance (Moriarty, 1997). Alternative strategies to prevent opportunistic infections are, therefore, strongly needed. The need of the hour is to search for novel antagonistic bacteria with therapeutic potential for which the pathogens may not have resistance. The genus Pseudomonas is one of the most diverse Gram negative bacterial genera isolated from sources ranging from plants, soils and water. A number of disease suppressive antibiotic compounds have been chemically characterised from pseudomonads. The chemical compounds vary with species and strains of Pseudomonas. In this study, attempts were made to study the in vitro antagonistic activity of a fish borne strain, Pseudomonas aeruginosa FARP72 against bacterial pathogens of human and fish and to characterise the bioactive secondary metabolites produced by the bacterial strain.

\section{Materials and methods}

Bacterial strains

An antagonistic bacterium Pseudomonas aeruginosa FARP72 (NCBI GenBank Accession no. KC570343) isolated from the skin mucus of freshwater catfish, Clarias batrachus (Hoque, 2015) was used for in vitro antagonistic activity against three bacterial pathogens of fish viz., Aeromonas caviae, Edwardsiella tarda and $\beta$-haemolytic Streptococcus sp. as well as 7 human bacterial pathogens viz., Bacillus pumilus, Escherichia coli, Enterohaemorrhagic E. coli, Klebsiella pneumonia, Salmonella Typhi (serovar of Salmonella enterica sub sp. enterica), Staphylococcus aureus ATCC 12598 and Vibrio cholerae. 
Ethyl acetate extraction of inhibitory substances of Pseudomonas aeruginosa FARP72

Ethyl acetate extraction as described in Wratten et al. (1977) was followed with minor modifications. $P$. aeruginosa FARP72 was inoculated onto six tryptic soy agar (TSA) plates and incubated for $48 \mathrm{~h}$ at $30 \pm 2^{\circ} \mathrm{C}$. The cells were then gently scraped off and washed with sterile saline. Centrifugation was done at 10,000 rpm for $15 \mathrm{~min}$ at $4^{\circ} \mathrm{C}$. Cell pellets were collected and suspended in $20 \mathrm{ml}$ ethyl acetate for $24 \mathrm{~h}$. Cells were removed by further centrifugation. The spent agar medium was cut into small pieces, homogenised with ethyl acetate $(300 \mathrm{ml})$ and allowed to stand for $48 \mathrm{~h}$ without agitation at $30 \pm 2^{\circ} \mathrm{C}$. The solvent was filtered through Whatman filter paper to remove the spent agar. Both solvents were decanted and evaporated using vacuum evaporator twice at $40-50^{\circ} \mathrm{C}$ at 15 psi to get a concentrated crude extract of the bacterial metabolites.

In vitro inhibitory activity of ethyl acetate extract of P. aeruginosa FARP72 cells and spent medium

The antibacterial activity of the crude ethyl acetate extracts of whole cells and spent medium was tested against test organisms by agar disc diffusion assay (CLSI, 2012). Bacterial lawns of the test organisms were prepared on TSA plates separately. Sterile discs of $6.0 \mathrm{~mm}$ dia were placed onto the TSA plates containing bacterial lawn. Aliquots $(3 \mu \mathrm{l})$ of the whole cell extract and spent medium extract were added separately onto the sterile discs and allowed to diffuse for $2 \mathrm{~h}$. The plates were incubated at $30 \pm 2^{\circ} \mathrm{C}$ for $24 \mathrm{~h}$ and examined for a definite zone of clearance around the discs.

Well diffusion assay was performed as described by Tagg and McGiven (1971). On TSA plates, wells of $0.5 \mathrm{~mm}$ dia each were cut using sterile borer. The bottom of the wells was sealed with $1 \mu \mathrm{l}$ of molten tryptic soya soft agar (tryptic soy broth $+0.8 \%$ agar). Thirty microlitre of the concentrated ethyl acetate extract of spent medium of $P$. aeruginosa FARP72 were added into each well. The extract was allowed to diffuse into the medium for $2 \mathrm{~h}$. The plates were then overlaid with $10 \mathrm{ml}$ of soft agar seeded separately with $10 \mu \mathrm{l}$ of overnight grown test organisms and allowed to set. The plates were then incubated at $30 \pm 2^{\circ} \mathrm{C}$ for $24 \mathrm{~h}$. The diameter of the inhibition zone in $\mathrm{mm}$ formed around the well was measured. Chloramphenicol disc $\left(30 \mu \mathrm{g} \mathrm{disc}^{-1}\right)$ was used as positive control.

Isolation and partial characterisation of ethyl acetate extract of P. aeruginosa FARP72

Crude ethyl acetate extract of $P$. aeruginosa FARP72 cells was subjected to column chromatography (CC). A glass column was packed with 100 g silica gel slurry dissolved in petroleum ether. The crude extract was adsorbed on to dry silica gel and the solvent was allowed to evaporate. Then the dry sample adsorbed to the silica gel was applied to the column packed with silica gel (60-120 mm mesh size). Different mobile phases were prepared separately using mixtures of solvents at different concentration viz., (i) petroleum ether, (ii) petroleum ether: ethyl acetate (1:2), (iii) petroleum ether: ethyl acetate (2:1) and (iv) ethyl acetate. A total of 25 fractions were collected. Solvents were removed from the fractions under reduced pressure using rotary evaporator. Thin layer chromatography (TLC) analyses of the crude material gave good separation of pigments on TLC plate in a solvent system that was composed of petroleum ether and ethyl acetate mixture. Therefore, the mixture was used in different combinations with increasing polarity to elute the column. The ethyl acetate crude extract was fractionated using silica gel TLC plates. TLC was performed on silica gel plates of $0.25 \mathrm{~mm}$ (60GF254 Merck) thickness as described by El-Mougith et al. (1986). The spots developed on TLC plates were visualised under UV light at 254 and $365 \mathrm{~nm}$ and then by exposure to iodine vapour. The fractions that showed the same TLC development profiles (colour and Rf) were combined and concentrated to dryness under reduced pressure using rotary evaporator. Time-of-flight mass spectrometry (TOF-MS) method was used in which the ion's mass-tocharge ratio was determined via time measurement. Ions were accelerated by an electric field which resulted in an ion having the same kinetic energy as any other ion that has the same charge. The velocity of the ion is dependent on the mass-to-charge ratio. The molecular weights of the compounds were elucidated based on mass spectral data. The compounds were identified by comparing molecular weight with the established data from the literature (Labows et al., 1980; Que et al., 2011; Charyulu et al., 2012).

\section{Results}

In vitro inhibitory activity of ethyl acetate extracts of whole cells of P. aeruginosa FARP72 and spent medium

The antibacterial substance from the whole cells and spent medium were extracted separately with ethyl acetate and both displayed inhibitory activity against the test organisms (Table 1; Fig. 1 and 2). The growth of Gram positive bacteria S. aureus ATCC 12598 and $B$. pumilus was inhibited by the crude extracts of $P$. aeruginosa FARP72. Crude extracts of $P$. aeruginosa FARP72 from spent medium effected larger zone of inhibition against the Gram negative bacterial pathogens of human origin such as V. cholerae, $S$. Typhi and E. coli with zone size ranging from 6 to $12 \mathrm{~mm}$. P. aeruginosa FARP72 showed inhibitory activity against the Gram 
Table 1. Susceptibility of human and fish pathogens to crude ethyl acetate extracts from P. aeruginosa FARP72

\begin{tabular}{|c|c|c|c|}
\hline \multirow{3}{*}{ Test strains } & \multicolumn{3}{|c|}{ Zones of inhibition (mm) } \\
\hline & \multicolumn{2}{|c|}{ Disc diffusion Assay } & \multirow{2}{*}{$\begin{array}{l}\text { Well diffusion Assay } \\
\text { Spent TSA } \\
\text { medium extract }\end{array}$} \\
\hline & $\begin{array}{l}\text { Whole cell } \\
\text { extract }\end{array}$ & $\begin{array}{l}\text { Spent TSA } \\
\text { medium extract }\end{array}$ & \\
\hline $\begin{array}{l}\text { Gram positive human pathogens } \\
\text { Bacillus pumilus }\end{array}$ & 8.00 & 8.00 & 23.50 \\
\hline Staphylococcus aureus ATCC $12598^{\mathrm{b}}$ & 9.00 & 9.00 & 20.00 \\
\hline $\begin{array}{l}\text { Gram negative human pathogens } \\
\text { Klebsiella pneumoniae }^{c}\end{array}$ & 9.00 & 10.00 & 21.00 \\
\hline Escherichia coli & 9.00 & 10.00 & 38.00 \\
\hline Vibrio cholerae $^{\mathrm{b}}$ & 8.50 & 12.00 & 20.00 \\
\hline Enterohaemorrhagic Escherichia coli & 8.00 & 7.00 & 24.00 \\
\hline Salmonella Typhi ${ }^{\mathrm{b}}$ & 9.00 & 10.00 & 28.50 \\
\hline $\begin{array}{l}\text { Gram positive fish pathogen } \\
\quad \beta \text { - haemolytic Streptococcus sp. }\end{array}$ & 8.00 & 7.00 & 30.00 \\
\hline $\begin{array}{l}\text { Gram negative fish pathogens } \\
\text { Aeromonas } \text { caviae }^{\mathrm{d}}\end{array}$ & 10.00 & 16.00 & 32.00 \\
\hline Edwardsiella tarda ${ }^{e}$ & 10.00 & 9.00 & 37.00 \\
\hline
\end{tabular}

TSA: Tryptic soy agar; a: Department of Fish Processing Technology, FFSc, Kolkata; b: Fisheries College and Research Institute, Tamil Nadu Fisheries University, Thoothukudi, c: Calcutta National Medical College and Hospital, Kolkata; d: Department of Aquatic Animal Health, FFSc, Kolkata; e: Shrimp Disease Diagnostic Laboratory, Tamil Nadu Fisheries University, Madhavaram, Chennai

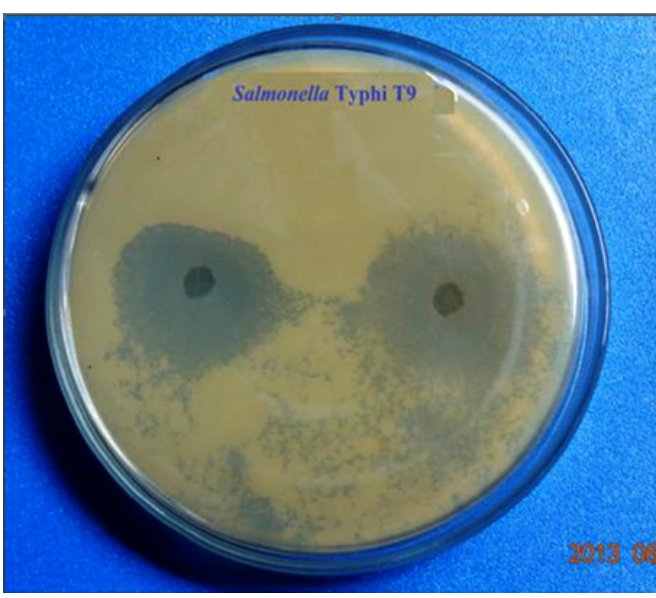

Fig. 1. In vitro inhibition of test strain T9, Salmonella Typhi by crude ethyl acetate extract of $P$. aeruginosa FARP72 spent medium by agar well diffusion assay

positive fish pathogen $\beta$-haemolytic Streptococcus sp. isolated from diseased Nile tilapia Oreochromis niloticus and Gram negative fish pathogens such as A. caviae and E. tarda. Largest zone of inhibition (10-16 mm) was shown against $A$. caviae. In all the cases, the ethyl acetate extract of the spent medium produced larger zones of inhibition as compared to whole cell extract.

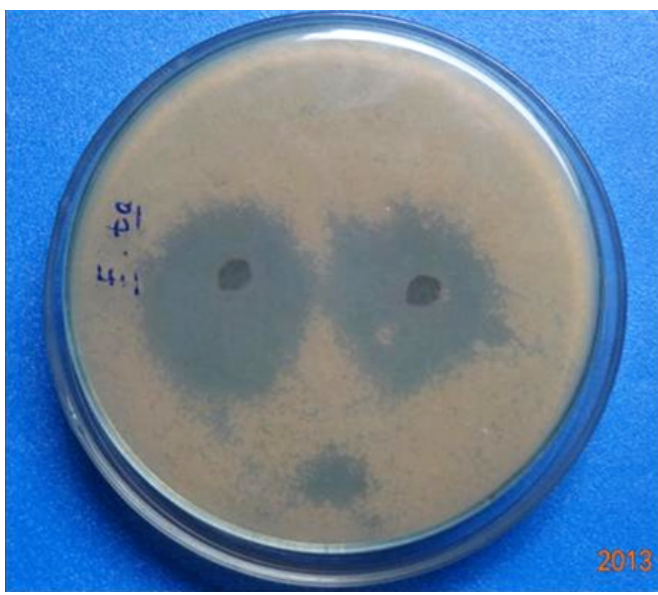

Fig. 2. In-vitro inhibition of test strain Edwardsiella tarda by crude ethyl acetate extract of $P$. aeruginosa FARP72 spent medium by agar well diffusion assay

Identification and characterisation of ethyl acetate extract of P. aeruginosa FARP72

From TLC results, fractions were combined according to their separation and finally, four fractions were obtained. First fraction (comprising 3-5 eluents) containing upper impurities were discarded. The second and fourth fractions (comprising 7-9 and 16-25 eluents, 
respectively) were considered to be partially pure. The third fraction (comprising 10-16 eluents) was considered to be mixture of second and fourth fractions. Molecular weights of the partially purified second and fourth fractions were established using the mass spectrum (MS). Due to the minute quantities of the bacterial extract obtained, analyses of the structure of the compounds were not possible by NMR. The peaks obtained by MS analysis were, therefore, compared with the literature references and the probable compounds were ascertained by molecular weight analysis. The column chromatography and MS profiles of the partially purified second fraction of $P$. aeruginosa extract (Fig. 3. and Table 2), showed intensity of the $\mathrm{m} / \mathrm{z} 144.08$ peak and hence was determined

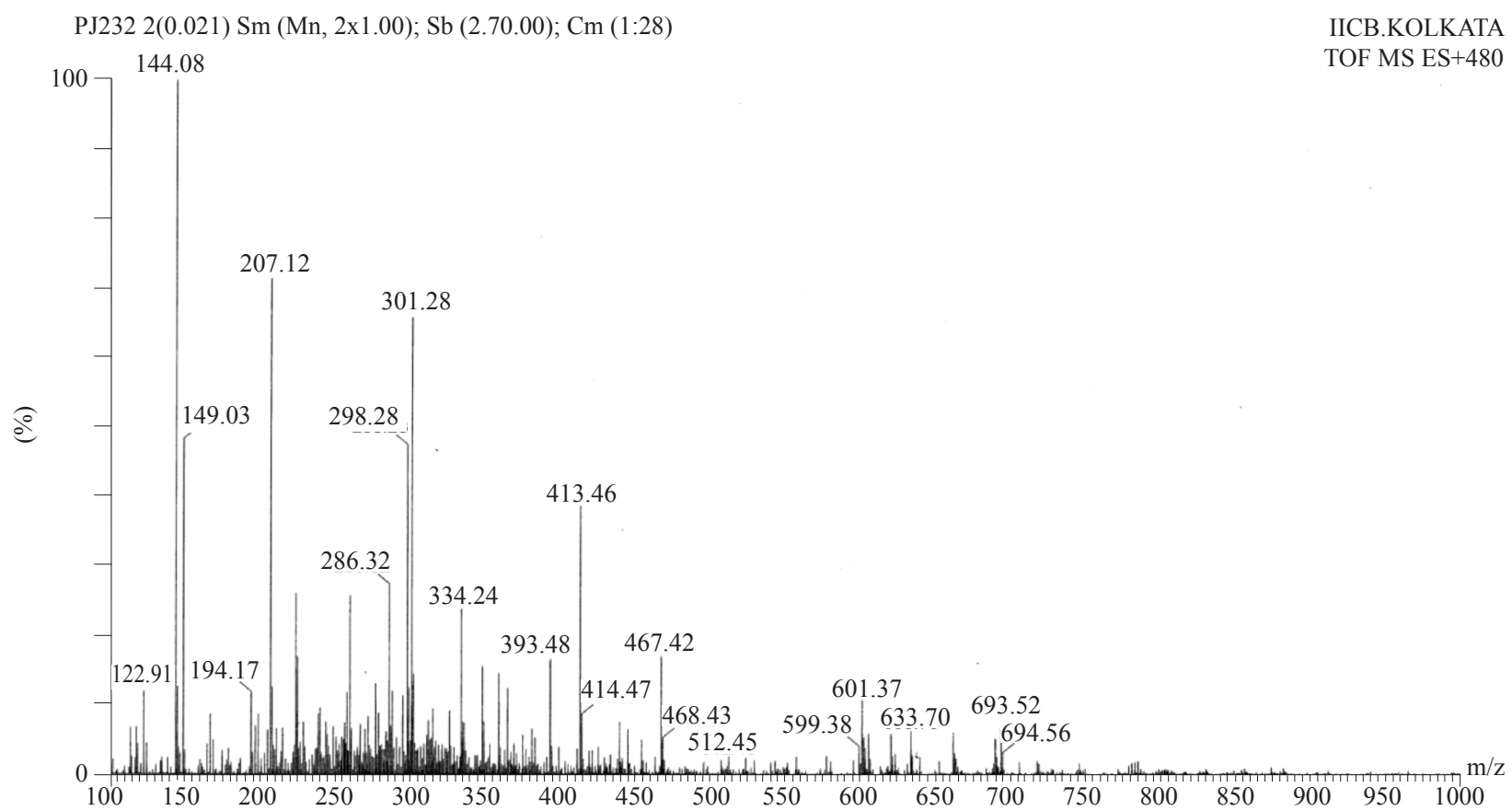

Fig. 3. Peaks obtained in Mass spectroscopy analysis of partially purified second fraction obtained by column chromatography of Pseudomonas aeruginosa FARP72 metabolites

Table 2. Identification of secondary metabolites of Pseudomonas aeruginosa P72 by mass spectral data Mass spectral data obtained in the fourth fraction

\begin{tabular}{llll}
\hline $\mathrm{m} / \mathrm{z}$ peak obtained & Compound name & References & Antimicrobial activity \\
\hline 260.27 & $\begin{array}{l}\text { Pyrrolnitrin }\left(\text { with loss of } \mathrm{H}^{+} \text {ions }\right) \text { or 3- } \\
\text { hydroxy tetra decanoic acid }\left([\mathrm{M}+\mathrm{NH} 4]^{+}\right) .\end{array}$ & $\begin{array}{l}\text { Itoh } \text { et al. }(1971) \\
\text { Maurhofer }(1992)\end{array}$ & + \\
& Pyoluteorin $\left(\left[\mathrm{M}+\mathrm{NH}_{4}\right]^{+}\right)$ & $*$ & + \\
288.32 & Pyocyanin $\left([\mathrm{M}+\mathrm{Na}]^{+}\right)$ & $*$ & + \\
244.25 & 3- hydroxy tetra decanoic acid & Que et al. $(2011)$ & + \\
315.35 & 4-hydroxy-2-heptayl quinoline & & + \\
\hline
\end{tabular}

Mass spectral data obtained in the second fraction

\begin{tabular}{|c|c|c|c|}
\hline 144.08 & 4-methyl quinazoline & $* *$ & + \\
\hline 207.12 & Phenazine-1-carboxylic acid & Labows et al. (1980) & + \\
\hline 149.03 & 3, 5,6-trimethyl pyrazine-2- carbaldehyde & Brown et al. (1955) & + \\
\hline 122.91 & 2, 3, 5-trimethyl pyrazine & Charyulu et al. (2012) & + \\
\hline 393.48 & 1, 1-diphenyl-2 picryl- hydrazyl radical & Charyulu et al. (2012) & + \\
\hline
\end{tabular}

*: http://www.chemicalbook.com/Chemical Product Property EN CB2135375.html

**: http://www.chemsynthesis.com/base/chemical-structure-8296.html 
to be 4-methyl quinazoline. Another peak recognised at $\mathrm{m} / \mathrm{z} 207.12$ supposed to be a phenazine-1-carboxylic acid with loss of one water molecule (Labows et al., 1980). A peak intensified at m/z 149.03 was identified as 3, 5, 6-trimethyl pyrazine-2- carbaldehyde with loss of $\mathrm{H}^{+}$ ion. The two compounds routinely detected in the mass spectral peak analysis was 2, 3, 5-trimethyl pyrazine and 1, 1- diphenyl-2 picryl- hydrazyl radical giving m/z 122.91 and 393.48, with loss of $\mathrm{H}^{+}$ion (Charyulu et al., 2012).

The partially purified fourth fraction as obtained from the ethyl acetate extract of $P$. aeruginosa FARP72 (Fig. 4 and Table 2) showed intensity of the $\mathrm{m} / \mathrm{z} 260.27$ peak in mass spectrum, which may be due to the presence of pyrrolnitrin (with loss of $\mathrm{H}^{+}$ions) or 3-hydroxy tetra decanoic acid $\left([\mathrm{M}+\mathrm{NH} 4]^{+}\right)$. P. aeruginosa produced a peak having $\mathrm{m} / \mathrm{z}$ value of $288.32\left([\mathrm{M}+\mathrm{NH} 4]^{+}\right)$and was identified as pyoluteorin. Pyocyanin and 3-hydroxy tetra decanoic acid were found in the same fraction having the intensity of $\mathrm{m} / \mathrm{z} 233.21\left([\mathrm{M}+\mathrm{Na}]^{+}\right)$and 244.25, respectively. Along with other peaks, another peak was obtained at $\mathrm{m} / \mathrm{z} 315.35$ due to the presence of 4-hydroxy2-heptayl quinoline (Que et al., 2011). ${ }^{+}$

\section{Discussion}

The in-vitro inhibitory activity of the antagonistic bacterium $P$. aeruginosa FARP72 against 10 pathogenic bacteria belonging to the genera Aeromonas, Bacillus, Edwardsiella, Escherichia, Klebsiella, Salmonella, Streptococcus and Vibrio were evaluated. Pseudomonas spp. is the most common genera associated with crustaceans (Moriarty, 1997) and are common inhabitants of the aquatic environment (Otta et al., 1999). They produce a wide range of secondary metabolites and used as biocontrol agents in several rhizosphere studies where their inhibitory activity has been attributed to a number of factors, such as the production of antibiotics, hydrogen cyanide or iron chelating siderophores (Raaijmakers et al., 1999). Torrento and Torres (1996) reported the in vitro inhibition of Vibrio harveyi by a Pseudomonas species isolated from the aquatic environment. As with their terrestrial counterparts, aquatic pseudomonads are often antagonistic to other microorganisms (Gram, 1993), including fish pathogenic bacteria (Smith and Davey, 1993) and fish pathogenic fungi (Bly et al., 1997). Chythanya et al. (2002) also reported inhibition of shrimp pathogenic vibrios by an estuarine strain of Pseudomonas, attributed to a low molecular weight, heat

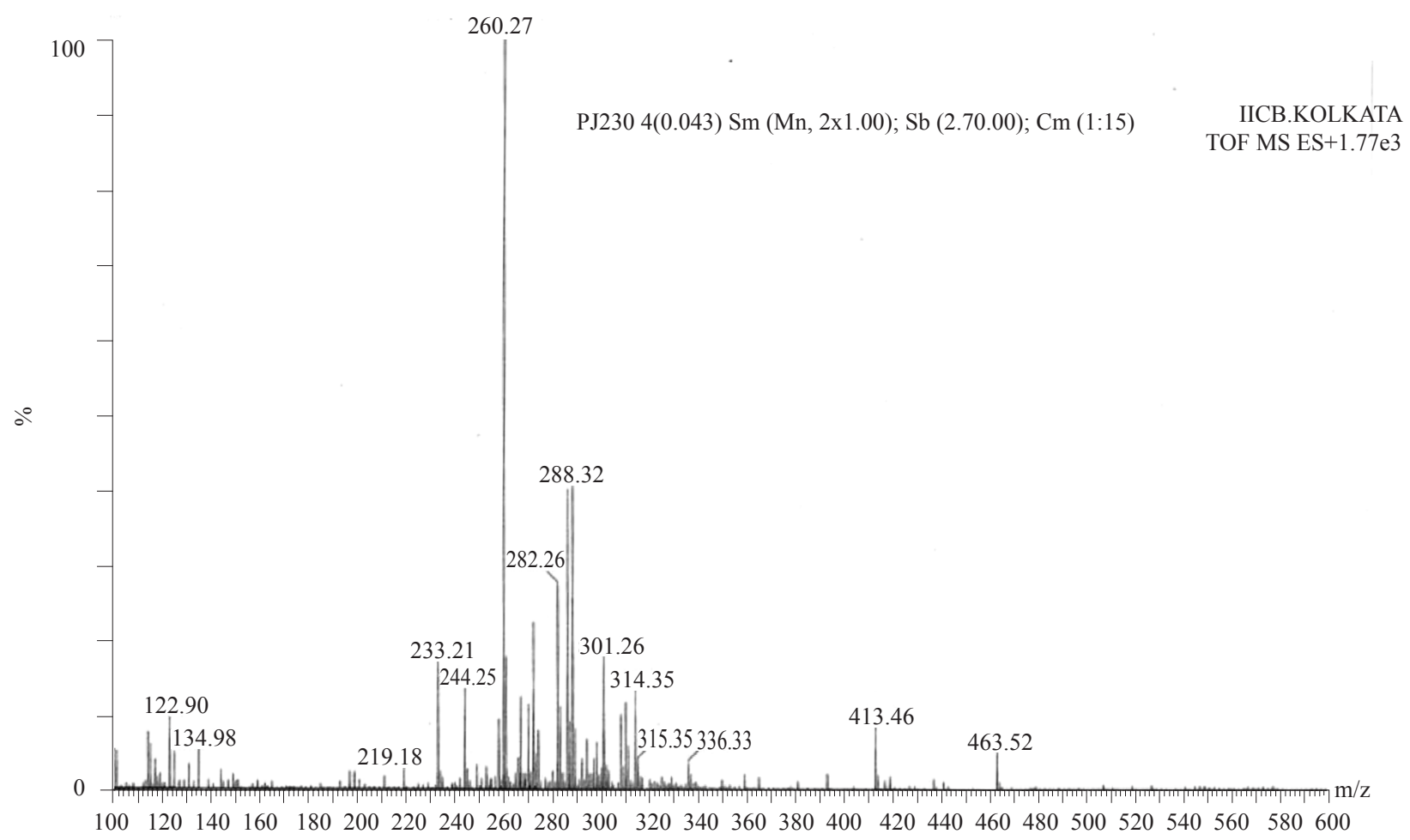

Fig. 4. Peaks obtained in Mass spectroscopy analysis of partially purified fourth fraction obtained by column chromatography of Pseudomonas aeruginosa FARP72 metabolites 
stable non-protein antimicrobial substance. The mode of action of Pseudomonas strains have been attributed to the production of several metabolites from different groups such as indoles (Kang et al., 2006), phenazines (Cazorla et al., 2006), pyocyanine, pyrrolnitrin (Ligon et al., 2000), pyolu-teorin, acetyl phloroglucinols (Raaijmakers et al., 1999; Guihen et al., 2004), tenzin (Nielsen et al., 2000), pseudotrienic acids A and B (Pohanka et al., 2005) and viscosinamide (Nielsen et al., 2000).

The inhibitory activity of $P$. aeruginosa FARP72 was more pronounced against Gram positive $S$. aureus ATCC 12598, followed by Gram negative A. caviae, E. tarda, Enterohaemorrhagic E. coli, E. coli, S. Typhi and $V$. cholerae. Results of earlier studies reported the dominance of Gram positive antagonistic bacteria in exhibiting broad spectrum action on Gram negative bacteria (Jack et al., 2005; Abraham and Banerjee, 2007). However, in the present study, it has been demonstrated that both Gram positive and Gram negative human and fish pathogens were inhibited by $P$. aeruginosa FARP72. This corroborated the findings of Kariminik and Baniasadi (2010), who demonstrated the in vitro antagonistic properties of six Gram positive soil bacteria against Gram negative and Gram positive pathogenic bacteria. Further, Giri et al. (2011) demonstrated antagonistic activity of three potential probiotic strains (Lactobacillus plantarum VSG3, $P$. aeruginosa VSG2 and $B$. subtilis VSG1) isolated from the intestine of Labeo rohita using well diffusion assay against $A$. hydrophila.

The crude ethyl acetate extracts of the whole cells and spent medium exhibited inhibitory activity on all tested bacterial strains at varying levels (Table 3.1). It can be inferred from the results that the antagonistic principle of $P$. aeruginosa FARP72 was of lipid origin. Comparable results of whole cells and spent medium extracts, as presented in Table 3.1, indicate only minor variations between the antimicrobial activities of crude whole cells and spent medium extracts. Ethyl acetate extract of the spent medium, which contains lipid molecules released into the medium, has given larger zone size compared to the whole cells (lipid molecules bound to the cell wall) extract against ten pathogenic test strains. The response of bacteria in terms of susceptibility to tested extracts and isolated compounds may vary among the strains due to genetic differences between the strains (Tamokou et al., 2012). However, in the present study, inhibition was noted irrespective of group, genus and species. Of the two Gram positive strains, maximum growth inhibition by the crude extracts of $P$. aeruginosa FARP72 was seen in $S$. aureus ATCC 12598 followed by B. pumilus. The crude extracts of $P$. aeruginosa FARP72 from spent medium effected larger zone $(6-12 \mathrm{~mm})$ of inhibition against $V$. cholerae,
S. Typhi and E. coli. P. aeruginosa FARP72 also proved its inhibitory activity against $\beta$-haemolytic Streptococcus sp., isolated from diseased $O$. niloticus as well as against A. caviae and E. tarda. It effected the largest zone of inhibition (10-16 $\mathrm{mm}$ ) against $A$. caviae. In all the cases, the ethyl acetate extract of the spent medium has shown larger zone of inhibition as compared to the whole cells extract.

Besides the production of antimicrobial lipids, $P$. aeruginosa might employ quorum-sensing-independent extracellular products (mainly polysaccharides) to disrupt established biofilms of pathogens (Qin et al., 2009). P. aeruginosa reportedly produces more than 55 quinolones/quinolines and these possess significant antibiotic activity against Gram positive bacteria (Deziel et al., 2004). Antimicrobial quinolines can be packaged into extracellular membrane vesicles to cause direct lysis of Staphylococcus (Mashburn and Whiteley, 2005). It has also been reported that $P$. aeruginosa can produce an organic compound: cis-2-decenoic acid, which is capable of inducing the dispersion of established biofilms and inhibiting biofilm development of many Gram positive and Gram negative bacteria (Davies and Marques, 2009). E. coli, K. pneumoniae, S. aureus and Salmonella have emerged to be the most problematic pathogens, with alarmingly high antibiotics resistance rates. Even with the most effective antibiotic against these pathogens, the resistance rates were detected (Tamokou et al., 2012). All these pathogens were found to be sensitive to the crude ethyl acetate extracts of $P$. aeruginosa FARP72. The overall results of this study can be considered as promising in the perspective of new drugs discovery from a natural source when considering the medical importance of the tested bacterial pathogens.

The genetics and biochemistry of pseudomonads, especially of $P$. aeruginosa have been explored intensively (Holloway et al., 1973). Apart from the pigments, most secondary metabolites produced by $P$. aeruginosa have been detected and investigated because of their antibiotic activity. The practical use of antibiotics from pseudomonads dates back to the period before the "antibiotic era." Emmerich and Low (1899) reported that the cell free culture fluid of $P$. aeruginosa, concentrated to one-tenth of its original volume, killed several kinds of bacteria. During the antibiotic era, approximately 50 different antibiotic substances from pseudomonads have been discovered (Berdy, 1974). Only two of these viz., pyocyanin and pyrrolnitrin, have been produced on a commercial basis. Most of them exhibit antibiotic or phytotoxic activity. Most antibiotics isolated from Pseudomonas culture filtrates, namely phenazines, pyrrolnitrin-type antibiotics, pyo compounds and indole 
derivatives, fall into the class of $\mathrm{N}$-containing heterocycles and have been shown to originate from intermediates or end products of the aromatic amino acid biosynthetic pathway (Leisinger and Margraff, 1977). Another substantial class of Pseudomonas secondary products comprises unusual amino acids and peptides (Dege, 2011). In addition to these two major groups of secondary metabolites, some glycolipids, lipids and aliphatic compounds have been isolated from Pseudomonas cultures (Abdel-Mawgoud et al., 2010). The peaks obtained by MS analysis of the present study were matched with already available literature and the probable compounds were ascertained by molecular weight analysis. The possibility of other compounds in the same peaks obtained in the second and fourth fractions, therefore, can not be ruled out.

The partially purified fourth fraction, obtained from the ethyl acetate extract of $P$. aeruginosa FARP72, in the present study produced a peak with $\mathrm{m} / \mathrm{z}$ value of $288.32\left([\mathrm{M}+\mathrm{NH} 4]^{+}\right)$, which may be pyoluteorin as per the descriptions of Maurhofer (1992). Pyoluteorin (Plt, 4,5-dichloropyrrol-2-yl 2,6-dihydroxyphenyl), a polyketide antibiotic was first identified and separated from $P$. aeruginosa in 1958 (Takeda, 1958). Pyoluteorin is an antibiotic toxic to Pythium ultimum and other plant pathogenic oomycetes and has been shown to be an important factor in the biological control of such pathogens (Maurhofer, 1992). Pyoluteorin functions as an inducer of its own production when present in a culture medium at an extremely low concentration (1.47 nm). In this respect, pyoluteorin can act as signalling molecules such as the A-factor of Streptomyces griseus (Horinouchi, 1999) or acyl homoserine lactones of Vibrio fischeri and Serratia liquefaciens (Eberl et al., 1996), which influence cell physiology and gene expression. In addition to its autoregulatory role, pyoluteorin influenced the production of at least one other secondary metabolite, 2,4-diacetylphloroglucinol, which also acts as an antimicrobial and can be completely dissolved in organic solvents (Wang et al., 2008).

The fourth fraction as obtained in the present study showed a peak with an intensity of $\mathrm{m} / \mathrm{z} 260.27$ in MS, which is considered to be major and the most purified compound, may be due to the presence of 3-hydroxy tetra decanoic acid $\left([\mathrm{M}+\mathrm{NH} 4]^{+}\right)$as described by Itoh et al. (1971). They belong to the class of rhamnolipids and are glycolipidic biosurfactants produced by various bacterial species. This fatty acid has also been identified as a constituent of the lipopolysaccharide layer of the outer membrane of certain Gram negative bacteria, including pseudomonads (Battu and Reddy, 2009). The compound is excreted into the medium during the stationary phase of growth and the optimal conditions for its formation from various carbon sources have been defined (Hauser and Karnovsky, 1957). They were initially found as exoproducts of $P$. aeruginosa (Abdel-Mawgoud et al., 2010). Biosurfactants are attracting much attention because they represent ecological alternatives to their synthetic counterparts, they exhibit lower toxicity, potentially high activities and stability at extremes of temperature, $\mathrm{pH}$ and salinity. Most importantly, they are biodegradable, making them environmentally friendly, "green" chemicals. Especially, they were shown to be active against a large variety of bacteria, including both Gram negative and Gram positive species, though the latter such as B. subtilis, are in general much more susceptible to the toxic effect of rhamnolipids (Itoh et al., 1971). Growth inhibition was also observed against Rhodococcus erythropolis and B. cereus (Arino et al., 1998). Various combinations of 3-hydroxy tetra decanoic acid displayed antimicrobial activity against nearly all tested Gram positive species, including Staphylococcus, Mycobacterium and Bacillus and significant activity against a number of Gram negative species, with Serratia marcescens, Enterobacter aerogenes and K. pneumoniae as specially sensitive ones. They also found an excellent inhibitory activity against a range of fungal species, including the filamentous fungi Chaetomium globosum, Aureobacidium pullulans and Gliocladium virens and the phytopathogens Botrytis cinerea and Rhizoctonia solanii, but no significant effect on yeasts (Benincasa et al., 2004).

Another peak was obtained in the fourth fraction at $\mathrm{m} / \mathrm{z} 315.35$, which may denote the presence of 4-hydroxy2-heptayl quinoline (Que et al., 2011). 4-Hydroxy-2alkylquinolines (HAQs), especially 3,4-dihydroxy-2heptyl quinoline (Pseudomonas quinolone signal) and its precursor, 4-hydroxy-2-heptyl quinoline, are attracting much attention, mainly because of their role as signalling molecules in $P$. aeruginosa. These molecules possess biological activities that endow the producer with increased fitness to compete with other species, infect various hosts and colonise diverse ecological niches. 4-Hydroxy-2-alkylquinolines (HAQs), originally named "pyo compounds," have been long known as a class of antimicrobials produced by the opportunistic bacterial pathogen $P$. aeruginosa (Coenye et al., 2003). A group of substances closely related to the pyo compounds was detected during the course of studies aimed at identifying a streptomycin antagonist excreted by $P$. aeruginosa (Sureau et al., 1948). The factor responsible for this antagonism was isolated and shown to consist of a mixture of 2-n heptyl-, 2-n nonyl- and 2-n undecyl-4-hydroxy quinoline N-oxides (Cornforth et al., 1956). These compounds, which probably correspond to pyo II, antagonised the inhibition by streptomycin and di-hydro streptomycin of B. subtilis and S. aureus but not of Gram negative 
bacteria. They were able to antagonise the action of 1,000 times their weight of di-hydro streptomycin and at higher concentrations inhibited the growth of Gram positive bacteria. Although the mode of action of the 2-alkyl-4hydroxyquinoline $\mathrm{N}$-oxides in antagonising the inhibitory action of di- hydro streptomycin has not been elucidated, it was observed that the compounds inhibited electron transport by cytochromes. This effect was assumed to be the reason for their inhibitory action on bacterial growth (Long et al., 2003).

In the fourth fraction, pyocyanin and 3-hydroxy tetra decanoic acid as per the descriptions in the literature (http:// www.chemicalbook.com/Chemical Product Property EN CB2135375.html) were found, which produced peaks with intensities of $\mathrm{m} / \mathrm{z} 233.21\left([\mathrm{M}+\mathrm{Na}]^{+}\right)$and 244.25, respectively. In vivo studies have shown that the growth of fungus was inhibited in the presence of pyocyanin (Kerr et al., 1998). The fungicidal mechanism is the activation of $\mathrm{NAD}(\mathrm{P}) \mathrm{H}$ to induce a redox active cascade to produce reactive oxygen intermediates. This allows $P$. aeruginosa to have a competitive advantage and it may dominate over other microorganisms. The synthesis of pyocyanin is primarily controlled by the quorum sensing process in $P$. aeruginosa strains (Mavrodi et al., 2012).

The second fraction of ethyl acetate extract of P. aeruginosa FARP72 also showed a peak with an intensity of $\mathrm{m} / \mathrm{z} 144.08$ peak, which may be 4-methyl quinazoline (http://www.chemsynthesis.com/base/chemi cal-structure-8296.html). It has been reported that $P$. aeruginosa has a distinct metabolism, part of which results in the production of bacteria-specific volatile organic compounds, which have proved their efficacy as antimicrobials and might be used for diagnostic purposes (Bos et al., 2013). Another peak was recognised at $\mathrm{m} / \mathrm{z}$ 207.12 supposed to be a phenazine-1-carboxylic acid with a loss of one water molecule (Labows et al., 1980). Phenazines have been implicated in the biocontrol of soilborne plant diseases by the introduction of pseudomonads and have proved their efficacy as strong antimicrobials, especially against plant pathogens like Gaeumannomyces graminis var. tritici (Mavrodi et al., 2012). The mode of action of Pseudomonas may be attributed to the production of phenazine compounds like phenazine-1-carboxylic acid (PCA), pyocyanin, 1-hydroxy phenazine (1-HP) and phenazine-1-carboxamide (Byng et al., 1979). Formation of phenazines by $P$. aureofaciens and $P$. aeruginosa may be accommodated in the pathway by assuming phenazine-1carboxylate as the second major branch point (Hansford et $a l ., 1972)$. This key intermediate would act as the precursor of pyocyanine, 1-hydroxyphenazine and its 10-monoxide, aeruginosins $\mathrm{A}$ and $\mathrm{B}$ and 2- hydroxyphenazine and its 1 -carboxylate. In the past few decades it has been proved that (i) phenazines function effectively as electron shuttles to Fe(III) minerals (Hollstein and McCamey, 1973), which may aid in Fe(II) acquisition; (ii) phenazines help modulate intracellular redox homeostasis as oxidants for $\mathrm{NADH}$ and/or by affecting carbon flux through central metabolic pathways; (iii) phenazines are signalling molecules, influencing the expression of a limited set of genes during the transition from exponential growth into stationary phase; (iv) phenazines are produced in biofilms, as expected, given that phenazine biosynthesis had previously been shown to be up-regulated by quorum sensing and low oxygen tension; and (v) phenazines play an important role in biofilm development, dramatically affecting the morphology of multicellular communities. Other phenazine derivatives from $P$. aeruginosa are redox-active compounds that exert many of their effects by altering oxidative metabolism and/or increasing the formation of reactive oxygen species [ROS] (Hassan and Fridovich, 1980). The ROS, in turn, can alter the function and gene expression of pathogenic bacteria (Brown, 1994).

Another peak obtained in the second fraction intensified at $\mathrm{m} / \mathrm{z} 149.03$ was identified as 3, 5, 6 trimethyl pyrazine-2- carbaldehyde with a loss of $\mathrm{H}^{+}$ion (Brown et al., 1955). In fraction "B", of the present study, the two compounds that gave $\mathrm{m} / \mathrm{z} 122.91$ and 393.48 with a loss of $\mathrm{H}^{+}$ion were detected in the mass spectral peak analysis, which corresponds to 2, 3, 5-trimethyl pyrazine and 1,1-diphenyl-2 picryl- hydrazyl radical (Charyulu et al., 2012). Pyrazines are widely distributed in nature, occur naturally and exhibit wide aromas. They are widely distributed in micro-organisms and act as antimicrobials (Beck et al., 2003). The pyrazine derivatives exhibiting antibacterial activity have also been synthesised. The activity of pyrazine derivative compounds towards 25 strains each of anaerobic and aerobic bacteria has been established (Gobis et al., 2006).

To summarise, the present study identified several antimicrobial compounds such as 4- methyl quinazoline; 3,5,6 -trimethyl pyrazine-2- carbaldehyde; 2,3,5-trimethyl pyrazine; 1,1- diphenyl-2 picryl- hydrazyl radical, phenazine-1-carboxylic acid, pyrrolnitrin, 4-hydroxy-2heptayl quinoline, pyocyanin, pyoluteorin and 3- hydroxy tetra decanoic acid from the two partially purified fractions of the ethyl acetate extracts of $P$. aeruginosa FARP72. All these compounds belonged to glycolipid, lipid and aliphatic derivatives, which exhibited antimicrobial activity. Nevertheless, the role of proteinaceous, carbohydrates and other antimicrobial compounds in the observed inhibition of the test bacteria in the present study could not be ruled out. However, it will be promising to separate the compounds in pure forms to explore their biological and surface activities for a variety of applications, which 
may unravel the biotechnological uses of these glycolipid biosurfactants, lipids and other aliphatic compounds either in pure form or in mixtures. Moreover, characterisation of the structure-activity relationship of these compounds might be useful for prediction of the behaviour of different natural rhamnolipids mixtures comprising one major congener among other minor congeners.

Antibiotic production by fish-borne $P$. aeruginosa FARP72 is recognised as an important feature in disease suppression. The evidence that secondary microbial metabolites play a key role in the biological control of certain human and fish pathogens provides a strong incentive to develop such compounds as biocontrol agents for commercial use. The use of microbial strains producing antibiotic metabolites in controlled environments offers the best possibility for disease management. The major challenges to be resolved prior to widespread commercial exploitation of biocontrol strains lies in the ability to predict more confidently the behaviour of such strains in the field. Fortunately, as interest in these organisms grows, more information on the genetics, physiology and ecology of metabolite production become available. Such data are of immense importance for the selection of wild type strains with desirable traits from nature and to provide a more rational framework for the choice of strains for use in microbial consortia.

\section{References}

Abdel-Mawgoud, A. M., Aboulwafa, M. M. and Hassouna, N. A. H. 2010. Characterisation of rhamnolipid produced by Pseudomonas aeruginosa isolate Bs20. Appl. Biochem. Biotechnol., 157: 329-345. doi: 10.1007/s12010-008-8285-1.

Abraham, T. J. and Banerjee, T. 2007. Beneficial antagonistic bacteria from freshwater fishes and culture environment as probiotics in ornamental fish culture. Indian J. Fish., 54: 311-319.

Arino, S., Marchal, R. and Vandecasteele, J. P. 1998. Involvement of a rhamnolipid-producing strain of Pseudomonas aeruginosa in the degradation of polycyclic aromatic hydrocarbons by a bacterial community. J. Appl. Microbiol., 84: 769-776. doi.org/10.1046/j.1365-2672.1998.00412.x

Battu, P. R. and Reddy, M. S. 2009. Isolation of secondary metabolites from Pseudomonas fluorescens and its characterisation. Asian J. Res. Chem., 2(1): 26-29.

Beck, H. C., Hansen, A. M. and Lauritsen, F. R. 2003. Novel pyrazine metabolites found in polymyxin biosynthesis by Paenibacillus polymyxa. FEMS Microbiol. Lett., 220: 67-73. DOI: 10.1016/S0378-1097(03)00054-5.

Benincasa, M., Abalos, A., Oliveira, I. and Manresa, A. 2004. Chemical structure, surface properties and biological activities of the biosurfactant produced by Pseudomonas aeruginosa LBI from soapstock. Antoni Van Leeuwenhoek
Int. J. Gen. Mol. Microbiol., 85: 203-215. DOI: 10.1023/B:ANTO.0000020148.45523.41.

Berdy, J. 1974. Recent developments of antibiotic research and classification of antibiotics according to chemical structure. Adv. Appl. Microbiol., 18: 309-407.

Bly, J. E., Quiniou, S. M. A., Lawson, L. A. and Clem L. W. 1997. Inhibition of Saprolegnia pathogenic for fish by Pseudomonas fluorescens. J. Fish Dis., 20: 35-40. doi. org/10.1046/j.1365-2761.1997.d01-104.x

Bos, L. D. J., Sterk, P. J. and Schultz, M. J. 2013. Volatile metabolites of pathogens: A systematic review. PLoS Pathog., 9(5): e1003311.

Brown, H. C., Baude, E. A. and Nachod, F. C. 1955 Determination of organic structures by physical methods, Academic Press, New York.

Brown, R. H. 1994. Superoxide dismutase in familial amyotrophic lateral sclerosis: models for gain of function. Curr Opin. Neurobiol., 3(2): 5841-5846.

Byng, G. S., Eustice, D. C. and Jensen, R. A. 1979. Biosynthesis of phenazine pigments in mutant, wildtype cultures of Pseudomonas aeruginosa. J. Bacteriol., 138: 846-852.

Cazorla, F. M., Duckett, S. B., Bergstroem, E. T., Noreen, S., Odijk, R., Lugtenberg, B. J., Thomas-Oates, J. E. and Bloem-berg, G. V. 2006. Biocontrol of Avocado dematophora root rot by antagonistic Pseudomonas fluorescens PCL1606 correlates with the production of 2-hexyl 5-propyl resorcinol. Mol. Plant-Microbe Interact., 19: 418-428. DOI: 10.1094/MPMI-19-0418.

Charyulu, E. M., Subramanian, J. and Arumugam, G. 2012 Antioxidant, antimicrobial profile of a secondary metabolite of Pseudomonas aeruginosa: ESR and spectrophotometric methods. Oxid. Antioxid. Med. Sci., 1(2): 119-126. doi: 10.5455/oams.200812.or.013.

Chythanya, R., Karunasagar, I. and Karunasagar, I. 2002. Inhibition of shrimp pathogenic vibrios by a marine Pseudomonas I-2 strain. Aquaculture, 208: 1-10. doi. org/10.1016/S0044-8486(01)00714-1.

CLSI 2012. Performance standards for antimicrobial disk susceptibility tests, Approved standard, $7^{\text {th }}$ edn., CLSI document M02-A11, 2012. Clinical and Laboratory Standards Institute, Pennsylvania, USA.

Coenye, T., Vandamme, P. and LiPuma, J. J. 2003. Ralstonia respiraculi $\mathrm{sp}$. isolated from the respiratory tract of cystic fibrosis patients. Int. J. Syst. Evol. Microbiol., 53(5): 1339-1342. DOI 10.1099/ijs.0.02440-0.

Cornforth, J. W. and James, A. T. 1956. Structure of a naturally occurring antagonist of dihydrostreptomycin. J. Biochem., 63: 124-130. DOI: 10.1042/bj0630124.

Davies, D. G. and Marques, C. N. 2009. A fatty acid messenger is responsible for inducing dispersion in microbial biofilms. J. Bacteriol., 191: 1393-1403. doi: 10.1128/JB.01214-08. 
Dege, N. 2011. Technology of bottled water. $3^{\text {rd }}$ edn. Willey and Blackwell, New York, p. 345-351.

Deziel, E., Lepine, F., Milot, S., He, J., Mindrinos, M. N., Tompkins, R. G. and Rahme, L. G. 2004. Analysis of Pseudomonas aeruginosa 4-hydroxy-2-alkylquinolines (HAQs) reveals a role for 4-hydroxy-2-heptylquinoline in cell-to-cell communication. Proc. Nat. Acad. Sci. USA., 101(5): 1339-44. DOI: 10.1073/pnas.0307694100.

Eberl, L., Winson, M. K., Sternberg, C., Stewart, G. S. A. B., Christiansen, G., Chhabra, S. R., Bycroft, B., Williams, P., Molin, S. and Givskov, M. 1996. Involvement of $\mathrm{N}$-acyl-L- homoserine lactone autoinducers in controlling the multicellular behaviour of Serratia liquefaciens. Mol. Microbiol., 20: 127-136. doi.org/10.1111/j.1365-2958.1996. tb02495.x.

El-Mougith, A., Fonvieille, J. L., Touze-Soulet, J. M., Dargent, R. and Montant, Ch. 1986. The effect of cytochalasin A on the lipid composition of Mucor mucedo. Arab GulfJ. Sci. Res., 4(1): 259-267.

Emmerich, R. and Low, O. 1899. Bakteriolytische enzyme als ursache der erworbenen immunität und die heilung von infectionskrankheiten durch dieselben. Zeitschrift für die gesamte Hygiene und ihre Grenzgebiete, 31: 1-65.

Giri, S. S., Sukumaran, V., Sen, S. S., Vinumonia, J., Banu, B. N. and Jena P. K. 2011. Antagonistic activity of cellular components of potential probiotic bacteria, isolated from the gut of Labeo rohita, against Aeromonas hydrophila. Fish Shellfish Immunol., 3(3-4): 214-222. DOI: 10.1007/ s12602-011-9078-3.

Gobis, K., Foks H., Kedzia, A., Wierzchowskab, M., Zwolskac, E. and Kope, A. 2006. Studies on pyrazine derivatives xlvii. synthesis and antibacterial activity of novel pyrazine derivatives with amidoxime moiety. Acta Pol. Pharm., 63(1): 39-46.

Gram, L. 1993. Inhibitory effect against pathogenic, spoilage bacteria of Pseudomonas strains isolated from spoiled and fresh fish. Appl. Environ. Microbiol., 59: 2197-2203.

Guihen, E., Glennon, J. D., Cullinane, M. and Gara, F. O. 2004. Rapid analysis of antimicrobial metabolites monoacetylphloro-glucinol and 2, 4-diacetylphloro-glucinol using capillary zone electrophoresis. Electrophoresis, 25: 1536-1542.

Hansford, G. S., Holliman, F. G. and Herbert, R. B. 1972. Pigments of Pseudomonas species IV. In vitro, in vivo conversion of 5-methylphenazinium-1-carboxylate into aeruginosin A. J. Chem. Soc., 1: 103-105.

Hassan, H. M. and Fridovich, I. 1980. Mechanism of the antibiotic action pyocyanine. J. Bacteriol., 141(1): 156-163.

Hauser, G. and Karnovsky, M. L. 1957. Rhamnose and rhamnolipid biosynthesis by Pseudomonas aeruginosa. J. Biol. Chem., 224: 91-105.
Holloway, B. W., Rossiter, H., Burgess, D. and Dodge, J. 1973. Aeruginocin tolerant mutants of Pseudomonas aeruginosa. Gene Res., 22(3): 239-253.

Hollstein, U. and McCamey, D. A. 1973. Biosynthesis of phenazines. II. Incorporation of (6-14C)-D-shikimic acid into phenazine-1-carboxylic acid and iodinin. J. Organic Chem., 38(19): 3415-3417. DOI: 10.1021/jo00959a041.

Hoque, F. 2015. Screening and characterisation of antagonistic Pseudomonas aeruginosa FARP72 as a potential probiotic agent. Indian J. Fish., 62(4): 80-90.

Horinouchi, S. 1999. $\gamma$-Butyrolactones that control secondary metabolism, cell differentiation in Streptomyces. Cellcell signaling in bacteria. ASM Press, Washington, D. C., p. 193-207.

Itoh, S., Honda, H., Tomita, F. and Suzuki, T. 1971. Rhamnolipids produced by Pseudomonas aeruginosa grown on n-paraffin (mixture of C12, C13 and C14 fractions). J. Antibiotic., 24: 855-859. DOI: 10.7164/antibiotics.24.855.

Jack, R. W., Tagg, J. R. and Ray, B. 2005. Bacteriocins of Gram-positive bacteria. Microbiol. Rev., 59: 171-200.

Kang, B. R., Yang, K. Y., Cho, B. H., Han, T. H., Kim, I. S., Lee, M. C., Anderson, A. J. and Kim, Y. C. 2006. Production of indole-3-acetic acid in the plant-beneficial strain Pseudomonas chlororaphis $\mathrm{O} 6$ is negatively regulated by the global sensor kinase GacS. Curr. Microbiol., 52: 473-476.

Kariminik, A. and Baniasadi, F. 2010. Pageantagonistic activity of Actinomycetes on some Gram negative and Gram positive bacteria. World Appl. Sci. J., 8(7): 828-832.

Kerr, J., Taylor, G., Rutman, A., Hoiby, N., Cole, P. and Wilson, R. 1998. Pseudomonas aeruginosa pyocyanin, 1-hydroxyphenazine inhibit fungal growth. J. Clin. Pathol., 52(5): 385387. DOI: 10.1136/jep.52.5.385.

Labows, J. N., McGinley, K. J., Webster, G. F. and Leyden, J. J. 1980. Head space analysis of volatile metabolites of Pseudomonas aeruginosa, related species by gas chromatography-mass spectrometry. J. Clin. Microbiol., 22(2): 521-526.

Leisinger, T. and Margraff, R. 1977. Secondary metabolites of the fluorescent pseudomonads. Microbiol. Rev., 43: 422-442.

Ligon, J. M., Hill, D. S., Hammer, P. E., Torkewitz, N. R., Hofmann, D., Kempf, H. J. and Van Pee, K. H. 2000. Natural products with antifungal activity from Pseudomonas biocontrol bacteria. Pest Manag. Sci., 56: 688-695. doi.org/10.1002/1526-4998(200008)56:8<688::AIDPS186>3.0.CO;2-V.

Long, R. A., Qureshi, A., Faulkner, D. J. and Azam, F. 2003. 2-n-Pentyl-4-quinolinol produced by a marine Alteromonas sp., its potential ecological and biogeochemical roles. Appl. Environ. Microbiol., 69: 568-576. doi: 10.1128/ AEM.69.1.568-576.2003. 
Mashburn, L. M. and Whiteley, M. 2005. Membrane vesicles traffic signals, facilitate group activities in a prokaryote. Nature, 437: 422425. DOI: 10.1038/nature03925.

Maurhofer, M., Keel, C., Schnider, U., Voisard, C., Haas, D. and Defago, G. 1992. Influence of enhanced antibiotic production in Pseudomonas fluorescens strain CHA0 on its disease suppressive capacity. Phyto-pathol., 82: 190-195.

Mavrodi, O. V., Mavrodi, D. V., Parejko, J. A., Thomashow, L. S. and Weller, D. M. 2012. Irrigation differentially impacts populations of indigenous antibiotic-producing Pseudomonas spp. in the rhizosphere of wheat. Appl. Environ. Microbiol., 32(2): 783214-783220.

Moriarty, D. J. W. 1997. The role of microorganisms in aquaculture ponds. Aquaculture, 151: 333-349. doi. org/10.1016/S0044-8486(96)01487-1.

Nielsen, T. H., Thrane, C., Christophersen, C., Anthoni, U. and Sorensen, J. 2000. Structure, production characteristics and fungal antagonism of tensin a new antifungal cyclic lipopeptide from Pseudomonas fluorescens strain 96.578. J. Appl. Microbiol., 89: 992-1001.

Otta, S. K., Karunasagar, I. and Karunasagar, I. 1999. Bacterial flora associated with shrimp culture ponds growing Penaeus monodon. J. Aquac. Trop., 14: 309-318.

Pohanka, A., Broberg, A., Johansson, M., Kenne, L. and Levenfors, J. 2005. Pseudotrienic acids A and B, two bioactive metabolites from Pseudomonas sp. MF381IODS. J. Nat. Prod., 68: 1380-1385. DOI: 10.1021/ np050243a.

Qin, Z., Yang, L., Qu, D., Molin, S. and Tolker-Nielsen, T. 2009. Pseudomonas aeruginosa extracellular products inhibit staphylococcal growth and disrupt established biofilms produced by Staphylococcus epidermidis. Microbiol., 155: 2148-2156. DOI: 10.1099/mic.0.028001-0.

Que, Y. A., Hazan, R., Ryan, C. M., Milot, S., Lepine, F., Lydon, M. and Rahme, L. G. 2011. Production of Pseudomonas aeruginosa intercellular small signalling molecules in human burn wounds. J. Pathol., 123- 127. doi: $10.4061 / 2011 / 549302$
Raaijmakers, J. M., Bonsall, R. F. and Weller, D. M. 1999. Effect of population density of Pseudomonas fluorescens on production of 2,4-diacetylphloroglucinol in the rhizosphere of wheat. Phytopathol., 89: 470-475.

Smith, P., and Davey, S. 1993. Evidence for the competitive exclusion of Aeromonas salmonicida from fish with stress inducible furunculosis by fluorescent pseudomonad. J. Fish Dis., 16(6): 521-524. doi.org/10.1111/j.1365-2761.1993. tb00888.x.

Sureau, B., Arquie, E., Boyer, F. and Saviard, M. 1948. Analysis of Pseudomonas aeruginosa producing 4-hydroxy-2alkylquinolines (HAQs). Ann. Ins. Pasteur. Paris, 75: 169-171.

Tagg, J. R. and McGiven, A. R. 1971. Assay system for bacteriocins. Appl. Microbiol., 21: 943-44.

Takeda, R. 1958. Pseudomonas pigments. II. Two pigments, 1-phenazine-carboxylic acid, hydroxychloraphine, produced by Pseudomonas aeruginosa T359. Hakko Kogaku Zasshi, 36: 280-290.

Tamokou, J. D. D., Mpetga, D. J. S., Lunga, P. K., Tene, M., Tane, P. and Kuiate, J.sR. 2012. Antioxidant, antimicrobial activities of ethyl acetate extract, fractions, compounds from stem bark of Albizia adianthifolia (Mimosoideae). BMC Complement. Altern. Med., 12: 99-102. DOI: 10.1186/1472-6882-12-99.

Torrento, M. and Torres, J. 1996. In vitro inhibition of Vibrio harveyi by Pseudomonas sp. isolated from aquatic environment. UPV J. Nat. Sci., 1: 130-138.

Wang, W., Lu, X., Qin, X. J., Zhang, X. H. and Xu, Y. Q. 2008. Solubility of pyoluteorin in water, dichloromethane, chloroform and carbon tetrachloride from 278.2 to 333.2. J. Chem. Eng. Data, 53(9): 2241-2243. DOI: 10.1021/ je800369k.

Wratten, S., Wolf, M., Anderson, R. and Faulkner, D. 1977. Antibiotic metabolites from a marine pseudomonad. Antimicrob. Agents Chemother., 11: 411-414. DOI: 10.11 28/AAC.11.3.411. 